\title{
Factor Analysis about Indonesian Students' Motivations to Study in China Based on Push-Pull Theory
}

\author{
Shuang Yang $(D$, Sheling Ye, and Haiyan Li \\ School of Foreign Languages and Tourism, Wuxi Institute of Technology, 1600 Gaolang Western Road, Wuxi, \\ 214121 Jiangsu, China \\ Correspondence should be addressed to Shuang Yang; yangsh@wxit.edu.cn
}

Received 17 November 2021; Revised 4 December 2021; Accepted 6 December 2021; Published 17 December 2021

Academic Editor: Xin Ning

Copyright (C) 2021 Shuang Yang et al. This is an open access article distributed under the Creative Commons Attribution License, which permits unrestricted use, distribution, and reproduction in any medium, provided the original work is properly cited.

\begin{abstract}
Based on the push-pull model, the study is aimed at testing 116 China (Jiangsu Province) overseas students' travel motivations with the methods of factor analysis $\ A N O V A$ analysis, and independent $t$-test to explain internal and external factors, which influence overseas students' travel decision, and further improve overseas students travel market. The results show that leisure and relaxation, togetherness and socialization, and knowledge and culture are top three push factors, while special festivals, historical sites, and financial budgets are top three pull factors. Among sociodemographic factors, gender differences, lengths of visit in China, and main income sources have significant differences in overseas students travel decisions. With "One belt, one road" initiative, travel industries should precisely understand overseas students traveling preferences, explore travelling market layout to balance economic benefits and cultural transmission, and develop overseas students' traveling destination groups.
\end{abstract}

\section{Introduction}

Parallel to communication about goods, technology, and culture, talents, notably overseas students, have become a significant part of floating population in global cultural exchange history. Number of overseas students to China has surged since the implementation of Road and Belt strategy [1]. To be specific, China has become the greatest destination country for overseas students in Asia in the year 2018, with 492 thousand overseas students. The number has increased 1.1 times compared with that in 2009 and has increased 10 times compared with that in 1990 (Ministry of Education of the People's Republic of China, 2019). Notably, growth rate of overseas students from Belt and Road countries in 2018 has reached up to $13.6 \%$ compared with last year (http://www.moe.gov.cn/jyb_xwfb/gzdt_gzdt/ s5987/201904/t20190412_377692.html). It is estimated that China, as a destination country for overseas students, will continue to bring out potential in the future, thereby culture, consumption, education, and life-relevant issues will become topics worthy further exploration.
Present researches about overseas students in China have stressed on cultural diffusion [2] and international education cooperation [1], including regional integration of overseas students education, improvement of higher education internationalization, accurate docking of overseas students education and regional development strategies, and construction of overseas students education cooperation ecosystem. However, considering social and economic diversification and sustainable development, despite great groups of language and culture learners, overseas students are also potential consumers and participants of global traveling market. According to researches, significant differences in travelling consumption behavior were found between overseas students and domestic Chinese students, including consuming expectation, access to traveling information, traveling types, ways, destinations, and staying time [3]. Nevertheless, researches about traveling decision behavior, psychological factors, and traveling motivations about overseas students in China are still limited [4], which deserve further exploration. Therefore, this study is expected to contribute to expansion of overseas students' traveling market, 
upgrade of international travel market, accurate positioning, and comprehensive development. Overseas students from Indonesia were selected as the study sample. Despite consideration of sample availability, Indonesia is a typical Southeast Asia country along the Belt and Road path. It is expected that research on Indonesian students' traveling behavior in China can help us understand the travel motivation of young people from Southeast Asia countries.

Based on push-pull theory, this study is aimed at exploring Indonesian students' intrinsic and extrinsic motivation in traveling in China. Purposes of this study include finding out specific motivations and their relation, exploring relationship between demographic features and traveling preference, so as to prioritize overall layout of overseas students traveling market, upgrade popularizing strategies, and provide potential reference for enhancing traveling attraction.

\section{Literature Review}

Researches on tourism behavior and its influencing factors are vital in understanding travelers' decision making and may provide scientific suggestions for tourism managers' decision-making [5]. Based on concepts defining traveling behavior and motivation like escaping-seeking conceptual frameworks, travel career ladder (TCL), travel career pattern (TCP) model, and push-pull model are most widely used models analyzing influencing factors of travel behaviors [6]. Notably, the push-pull model is widely adopted to explain factors, which may influence tourists' traveling decision-making and other related behaviors [7-9]. Besides, the push-pull model is effective in learning destinationrelated as well as tourist-related factors, which is intuitive, and is frequently adopted in studies about travelers' behavior. Therefore, push-pull is an effective model and can serve as a simple and practical method in studying influencing factors of overseas students' traveling behavior.

Put forward by Bague in 1950s, push-pull theory was among fundamental theories in studying population mobility and immigration. Dann [10] came up with the pushpull model based on drive inducement theory, which established its status in tourism research [10]. In light of the push-pull model [11-15], scholars have classified influencing factors of traveling behavior into two categories, namely, push factors [16-19] and pull factors [20-23], and further summarized dominant influencing factors, respectively (Table 1) [24-26].

Uysal and Hagan [27] viewed push factors as tourists' inner demands, which are usually caused by needs of escape, relax, reputation, health, adventure, social contact, family reunion, and self-adjustment and are nonselective [27]. In addition, most push factors were intrinsic and inherent, like escaping from reality, eager for social contact, showing off social status, and exploring for new experience and knowledge. Dann [10] defined push factors as inner confusion and self-improvement [10]. Specifically, inner confusion tends to impel individuals to travel for escaping from reality and contacting others, while self-improvement refers to elevating self value, social status, and self-esteem through traveling. Crompton [17] believed that being eager to escape from reality, exploring new experience, and learning new knowledge are among dominant influencing aspects of pull factors [17]. Likewise, Goossens [18] pointed out that pull factors are related to inner driving power, feelings, and instinct, and tourists are inclined to escape from normal life, seek for unusual experience, relax, and adjust themselves [18]. Moreover, Iso-Ahola [15]'s empirical study also proved above ideas and highlighted escaping from reality, seeking for new experience, and getting rid of normal life are fundamental motivations and key elements of push factors [15].

Conversely, pull factor is closely related to destination attributes and is caused by tourists' understanding about the destination. Affected by destination attributes like infrastructure, specific activities, and climate conditions, pull factors are extrinsic incentives with certain directivity. Fakeye and Crompton [22] once carried out research in Texas tourist spot and discovered that destination attributes like snowy environment and sports infrastructure were distinct attraction for tourists [22]. McGehee and colleagues [28] found other pull factors like unique natural and cultural scenery, special cuisine, local customs, and practices [28]. Likewise, Kozak [23] and Kim et al. [29] mentioned factors like natural scenery, sunshine, and climate conditions served as important pull factors for tourists [23, 29]. Turnbull and Uysal [20] studied Caribbean resorts and identified difference in 6 types of extrinsic factors perception among foreign tourists [20]. Yi [30] and colleagues studied Fujian Adobe Residence and found that experiencing local culture and association with local residents were two dominant attractions for tourists, which are in line with previous findings [30].

To conclude, push factors can be defined as inner desires caused by intrinsic wishes or imbalance and vary in different destinations. Pull factors vary due to different destinations, which deserve further investigation. Both push and pull factors can explain how tourists are "pushed" by intrinsic factors and how they are "pulled" by extrinsic factors related to destinations. Experts from home and abroad have made great progress in the push-pull model and variables, but empirical researches in certain regions and about overseas students in China are still deficient. In the future, common and particular factors in individuals, global, and regional factors should be further discussed in critical framework, thereby optimize and refine impact factors.

In light of push-pull factor analysis from home and abroad, this study is aimed at improving the current theory structure through analyzing Indonesian students in China, thereby providing new perspectives for future researches.

\section{Research Method}

In order to better explore push and pull variables among the Indonesian students sample, indepth interview was conducted among a group of Indonesian students, who were studying in China. Word frequency analysis was followed to refine key push and pull motivators. Combined with previous literature and extant questionnaires upon the pushpull model, a new questionnaire was designed specifically for the Indonesian sample. After the distribution procedure 
TABLE 1: Main sources of push-pull model variables.

\begin{tabular}{|c|c|c|}
\hline Motivation & Variables & Sources \\
\hline \multirow{7}{*}{ Push factors } & Escape from live and work & Ross and Iso-Ahola, 1991 [11] \\
\hline & Physical and mental heath & Hallab, $2006[12]$ \\
\hline & New experience and knowledge & Fodness, 1994 [13]; Lee and Crompton, 1992 [14] \\
\hline & Prestige & Dann, 1997 [10]; Iso-Ahola, 1982 [15] \\
\hline & Novelty & Wang De-gen, $2004[16]$ \\
\hline & Leisure & Crompton, 1979 [17]; Goossens, 2000 [18] \\
\hline & Socialization and emotional communication & Phau et al., 2013 [19] \\
\hline \multirow{8}{*}{ Pull factors } & City image & Turnbull and Uyal, $1995[20]$ \\
\hline & Historical culture and custom & Zhang and Lam, 1999 [9]; Chen and Chen, 2011 [21] \\
\hline & Natural scenery & Fakeye and Cromptom, 1991 [22]; Kozak, 2002 [23] \\
\hline & Hospitality and local foods & Fakeye and Cromptom, $1991[22]$ \\
\hline & Entertainments and shopping & Wang Yingchuan and Lo You, 2015 [24] \\
\hline & Transportation and accommodation & Fakeye and Cromptom, 1991 [22] \\
\hline & Marketing image & Azman and Chan, $2010[25]$ \\
\hline & Tourist spots, infrastructure, activities, and climate & Phau et al., 2013 [19]; Prayag, 2012 [26] \\
\hline
\end{tabular}

of questionnaire, data was processed to find out the most influential push and pull motivators.

In view of extant literature and questionnaires, which were referred by many scholars, some push-pull variables were replaced according to results of word frequency analysis. Such changes were made in order to show Indonesian students' push and pull motivators in a more objective and scientific way. Furthermore, both qualitative and quantitative research methods were adopted during the empirical study to avoid biased results and to present scientific results of Indonesian students' motivators.

3.1. Scale Design and Procedure. This part consists of two procedures, indepth interview and word frequency analysis. From September to October in 2019, 16 Indonesian students in China were interviewed face-to-face, and interview questions outline is as follows (question 1 and 3 target at push factors and question 2 and 4 target at pull factors).

A quantitative survey questionnaire written in English that addresses the issue:

(1) What are the push motivations when you choose your destination in China?

(2) What are the pull motivations when you choose your destination in China?

(3) What experience or feelings do you expect from the travel in China?

(4) Which kind of travel destination in China attracts you most?

Firstly, 1593 words about push factors and 2079 words about pull factors were summarized after collecting interview information, among which 23 push-related and 33 pull-related high frequency words were refined. Top 10 push factors were knowledge, relax, culture, interest, society, explore, togetherness, experience, outlook, and opportunity. Meanwhile, top 10 pull factors were safety, culture, nature, leisure, activity, history, budget, outdoor scenery, religion, propaganda, and technologies.
Secondly, optimize content and structure of the scale. According to push-pull structure tested by scholars, vague expressions like social culture, culture, relax, leisure, and economy are redefined. Meanwhile, some tourism-related factors like discount air tickets, souvenir collection, and online traveling system development were included in influencing factors to optimize content and structure of the questionnaire. Final version of the questionnaire includes two parts, sociodemographic information and push-pull scales. Specifically, 21 push factors and 33 pull factors were tested with 5-point Likert scale varying from 1 (Strongly disapprove) to 5 (strongly approve).

3.2. Data Collection. In November 2019, 150 questionnaires were given out to Indonesian overseas students in Jiangsu province, and 124 questionnaires were collected, among which 116 are valid. In addition, 64 questionnaires were paper-based, while 51 were Internet-based.

3.3. Research Method. With SPSS22.0, we carried out validity test, KMO test, and exploratory factor analysis to find out predominant influencing factors of traveling. Furthermore, independent sample $t$-test and ANOVA single-factor variance analysis method were adopted to explore relationship between sociodemographic feature and traveling behavior.

3.4. Sociodemographic Feature of Sample. As can be seen from Table 2, 33.6\% of the samples were males, and $66.4 \%$ were females. $74.1 \%$ of the samples were youths younger than 20 years old with small age gap. Concerning educational attainment, higher vocational students accounted for $80.2 \%$, followed by $16.3 \%$ undergraduates and $2.6 \%$ graduate students. Meanwhile, three quarters samples came to study in China in 2018, and one quarter samples came to China in 2019. Among these overseas students, $71.6 \%$ of them chose to stay in China for one or two years, and $12.9 \%$ of them stayed over 2 years. Besides, $69.8 \%$ of the samples have 
TABLE 2: Sociodemographic characteristics of the respondents.

\begin{tabular}{|c|c|c|c|c|c|}
\hline Characteristics & Frequency & Percent (\%) & Characteristics & Frequency & Percent (\%) \\
\hline Gender & & & Time arrived in China & & \\
\hline Male & 39 & 33.6 & 2018 & 87 & 75 \\
\hline Female & 77 & 66.4 & 2019 & 29 & 25 \\
\hline Age & & & Length of visit in China & & \\
\hline Less than 20 & 86 & 74.1 & Less than 6 months & 9 & 7.8 \\
\hline $20-25$ years & 30 & 25.9 & 6-12 months & 9 & 10.8 \\
\hline Education level & & & $12-24$ months & 83 & 71.6 \\
\hline Postgraduate & 3 & 2.58 & More than 24 months & 15 & 9.9 \\
\hline Undergraduate & 19 & 16.3 & Monthly income (RMB) & & \\
\hline College & 97 & 83.7 & Less than 1000 & 81 & 69.8 \\
\hline Sources of income & & & 1001-15000 & 20 & 17.2 \\
\hline Gov. scholarship & 22 & 17 & $1501-2000$ & 9 & 7.8 \\
\hline College scholarship & 2 & 1.7 & 2000 & 6 & 5.2 \\
\hline Family support & 92 & 79.3 & & & \\
\hline
\end{tabular}

over 1000 RMB monthly disposable income, while only $5.2 \%$ of the samples have over 2000 RMB. In addition, $79.3 \%$ of these students rely on family income, followed by government scholarship, which accounted for $17 \%$.

\section{Data Analysis and Results}

4.1. Information and Validity Analysis. Push and pull factors' Cronbach's $\alpha$ indexes were 0.848 and 0.856 , respectively, which implied good internal consistency and high validity. Results of factor analysis showed that KMO of push and pull factors was 0.772 and 0.833 , respectively, which also indicated good factor analysis results. Significance of Bartlett's sphere test was 0.000 . To summarize, the questionnaire enjoyed good structural validity, which fits further factor analysis.

4.2. Significance Analysis of Push-Pull Factors. Influencing levels of push-pull factors on samples' traveling behavior can be seen according to mean value order (Table 3). Among push factors, share feelings with families and friends stood in the first place with 4.431 mean value, followed by refreshing feelings $(M=4.310)$ and exploring something unknown $(M=4.302)$. That is to say, sharing and accompany are predominant inner feelings of respondents and followed by enriching spiritual demands through attaining new experiences, broadening their horizons, and experiencing something unknown. Attraction of local cuisine $(M=4.293)$ took the first place among pull factors, and technological development $(M=4.164)$ and famous events $(M=4.155)$ came next. In other words, cuisine was a leading attraction for respondents' traveling behavior, and adoption of technology and intelligence also played an important role in "pulling" travelers.

4.3. Push Factor Analysis. We carried out exploratory factor analysis and conditioned characteristic root $>1$ and factor loading $>0.5$ to eliminate indicators that do not meet the requirements and obtained 20 push and 31 pull factors
(Table 4). On basis of that, the PCA and maximum orthogonal rotation method was adopted to extract push and pull attribute dimensions. Finally, we got 6 push factors and 7 pull factors with cumulative variance contribution rate of $76.875 \%$ and $75.363 \%$, respectively, which indicated that each index can be expressed by common factors. 6 push factors are as follows: leisure and escape from current situation, accompany and socialization, knowledge and culture, exploration of new experience, personal interest, and inner feelings and emotions.

According to comparison of cumulative variance contribution rate, "leisure and escape from current situation $(M=4.06, \mathrm{SD}=0.75)$ " had the greatest effect on respondents' choice of traveling, followed by "accompany and socialization $(M=4.193, \mathrm{SD}=0.79)$." "Knowledge and culture $(M=4.06, \mathrm{SD}=0.75)$ " and "Exploration of new experience $(M=3.96, \mathrm{SD}=0.73)$ " ranked 3 and 4 , respectively, which showed respondents' strong desire for exploration of exotic culture and challenge new environments. The fifth factor "personal interest $(M=3.79, \mathrm{SD}=0.76)$ showed significant relationship between interest and traveling preference. Moreover, the sixth factor "inner feelings and emotion $(M=3.46, \mathrm{SD}=0.81)$ " indicated that respondents tended to show their social status through traveling behavior.

4.4. Pull Factor Analysis. 7 pull factors are as follows (Table 5): activities and events, historical and cultural resorts, budgets, safety and infrastructure, convenience service, nature, and source of propaganda. According to order of variance contribution rate, activities and events ranked first with $19.93 \%$ and followed by historical and cultural resorts with $14.1 \%$. Meanwhile, the sixth factor "nature" $(M=3.574, \mathrm{SD}=0.892)$ was less attractive than historical and cultural resorts. The third factor "budget $(M=3.92$, $\mathrm{SD}=0.84)$ " ranked first in mean value, which indicated significant pulling effect of cost effect on respondents, including full use of visa, special discount, and exchange rate. The fourth factor "safety and infrastructure $(M=3.89, \mathrm{SD}=$ 
TABle 3: Top 10 important push factors and pull factors.

\begin{tabular}{lccc}
\hline Rank & Push factors & $M$ & Pull factors \\
\hline 1 & Share feelings & 4.431 & Delicious local cuisine \\
2 & Refreshing feelings & 4.310 & Well-developed technology \\
3 & Explore something unknown & 4.302 & Famous events \\
4 & Delicious local cuisine & 4.250 & High standard of hygiene \\
5 & Desire for difference & 4.095 & Tour around the destination \\
6 & Relaxing time & 4.052 & Famous historic sites \\
7 & Pursuit for special moments & 4.034 & 4.078 \\
8 & Curiosity & 3.991 & Special offer or coupon \\
9 & Participation of families and friends & 3.940 & Cost effectiveness \\
10 & Desire to broaden horizon & 3.793 & Available holidays \\
\hline
\end{tabular}

TABle 4: Push motive of Indonesia overseas students' traveling $(N=116)$.

\begin{tabular}{|c|c|c|c|c|c|c|c|}
\hline \multirow{2}{*}{ Motivation } & \multicolumn{6}{|c|}{ Factor loading } & \multirow[t]{2}{*}{$M(\mathrm{SD})$} \\
\hline & 1 & 2 & 3 & 4 & 5 & 6 & \\
\hline 1 Leisure and escape & & & & & & & $4.060(0.751)$ \\
\hline Relaxing time & 0.720 & & & & & & \\
\hline Refreshing feeling & 0.830 & & & & & & \\
\hline Escape from current situation & 0.631 & & & & & & \\
\hline Desire for difference & 0.597 & & & & & & \\
\hline 2 Togetherness and socialization & & & & & & & $4.193(0.794)$ \\
\hline Participation of families and friends & & 0.732 & & & & & \\
\hline Share feelings & & 0.639 & & & & & \\
\hline 3 Knowledge and culture & & & & & & & $4.062(0.753)$ \\
\hline Understand the history & & & 0.799 & & & & \\
\hline Deep understand of destination & & & 0.598 & & & & \\
\hline Understand cultural value & & & 0.771 & & & & \\
\hline 4 Exploration & & & & & & & $3.963(0.732)$ \\
\hline Opportunity for life or career & & & & 0.692 & & & \\
\hline Desire to broaden horizon & & & & 0.816 & & & \\
\hline Exploration & & & & 0.516 & & & \\
\hline 5 Personal interest & & & & & & & $3.791(0.763)$ \\
\hline Cuisine/food/taste & & & & & 0.863 & & \\
\hline Shopping/consumption desire & & & & & 0.621 & & \\
\hline Collect (specific souvenir) & & & & & 0.859 & & \\
\hline 6 Inner feelings and emotion & & & & & & & $3.464(0.814)$ \\
\hline Self-selection & & & & & & 0.524 & \\
\hline Show status & & & & & & 0.913 & \\
\hline Feeling superiority & & & & & & 0.896 & \\
\hline Curiosity & & & & & & 0.642 & \\
\hline Eigenvalue & 4.708 & 3.064 & 2.543 & 1.969 & 1.438 & 1.372 & \\
\hline Variance contribution & 22.418 & 17.590 & 12.110 & 9.378 & 8.847 & 6.532 & \\
\hline Cronbach's $\alpha$ & 0.870 & 0.860 & 0.830 & 0.850 & 0.790 & 0.890 & \\
\hline
\end{tabular}

0.75)" showed that stable social environment, hygiene, traffic safety factors are obviously attractive to respondents. The fifth factor "convenience service $(M=3.76, \mathrm{SD}=0.89)$ " includes various vocations, ample leisure time, convenient travel service, online travel ticketing, and hotel reservation service, which may greatly eliminate traveling barriers, thereby stimulate travel behavior. Comparatively speaking, variance contribution rate of the seventh factor "source of propaganda $(M=3.42, \mathrm{SD}=0.83)$ " was the lowest, which indicated low pulling influence website, billboard propaganda, and friends' recommendation on Indonesian students traveling behavior in China. 
TABle 5: Pull motive of Indonesia overseas students' traveling $(N=116)$.

\begin{tabular}{|c|c|c|c|c|c|c|c|c|}
\hline \multirow{2}{*}{ Motivation } & \multicolumn{7}{|c|}{ Factor loading } & \multirow{2}{*}{$M(\mathrm{SD})$} \\
\hline & 1 & 2 & 3 & 4 & 5 & 6 & 7 & \\
\hline Factor 1: activities/events & & & & & & & & $3.891(0.842)$ \\
\hline Outdoor sports events & 0.823 & & & & & & & \\
\hline Special festivals & 0.795 & & & & & & & \\
\hline Famous events & 0.761 & & & & & & & \\
\hline Delicious local food/cuisine & 0.707 & & & & & & & \\
\hline Visit friend or people & 0.585 & & & & & & & \\
\hline Factor 2: historical/cultural aspects & & & & & & & & $3.645(0.791)$ \\
\hline Local life style & & 0.902 & & & & & & \\
\hline Local religion & & 0.876 & & & & & & \\
\hline Local crafts/specialty & & 0.781 & & & & & & \\
\hline Rich local tradition & & 0.747 & & & & & & \\
\hline Famous historic sites & & 0.738 & & & & & & \\
\hline Tour around the destination & & 0.603 & & & & & & \\
\hline Factor 3: budget & & & & & & & & $3.926(0.843)$ \\
\hline Current exchange rate & & & 0.779 & & & & & \\
\hline Cost effective & & & 0.822 & & & & & \\
\hline Discounts of tourist spots & & & 0.805 & & & & & \\
\hline Full use of visa & & & 0.777 & & & & & \\
\hline Factor 4: safety and infrastructure & & & & & & & & $3.898(0.754)$ \\
\hline Development of society & & & & 0.849 & & & & \\
\hline Safety of society & & & & 0.721 & & & & \\
\hline High standard of hygiene & & & & 0.734 & & & & \\
\hline Traffic safety & & & & 0.857 & & & & \\
\hline Factor 5: convenience service & & & & & & & & $3.762(0.891)$ \\
\hline Available holidays/weekend & & & & & 0.820 & & & \\
\hline Developed IT & & & & & 0.914 & & & \\
\hline Infrastructure & & & & & 0.758 & & & \\
\hline Travel insurance & & & & & 0.652 & & & \\
\hline Package of travel agency & & & & & 0.887 & & & \\
\hline Factor 6: Nature & & & & & & & & $3.574(0.892)$ \\
\hline Fresh air & & & & & & 0.822 & & \\
\hline Sparse population & & & & & & 0.877 & & \\
\hline Agreeable weather & & & & & & 0.663 & & \\
\hline Natural beauty & & & & & & 0.729 & & \\
\hline Factor 7: source of propaganda & & & & & & & & $3.420(0.830)$ \\
\hline Ads from web/billboards & & & & & & & 0.865 & \\
\hline Recommendation from others & & & & & & & 0.799 & \\
\hline Eigenvalue & 7.598 & 4.033 & 3.717 & 2.702 & 2.530 & 2.036 & 1.897 & \\
\hline Variance contribution & 19.934 & 14.191 & 11.213 & 9.180 & 8.650 & 6.462 & 5.733 & \\
\hline Cronbach's $\alpha$ & 0.893 & 0.856 & 0.881 & 0.790 & 0.842 & 0.872 & 0.861 & \\
\hline
\end{tabular}

4.5. Influence of Sociodemographic Feature on Traveling Behavior. Exploration on relationship between sociodemographic feature and travel preference is among objectives of this study. We adopted independent sample $t$-test and ANOVA single factor test to explore whether there were significant differences between travel preference and respondents' gender, age, educational attainment, staying time length in China, arriving time to China, and disposable income source, thereby condition significance value $P<$ 0.05 to find out significant differences between Indonesian overseas students' travel preference and gender, staying time length in China, and main income source.

4.5.1. Influence of Gender on Push-Pull Factors. According to result of independent sample $t$-test on gender, males and females showed significant differences in 2 push factors, 
TABLE 6: Influence of visit length in China \main income source to push-pull factors.

\begin{tabular}{|c|c|c|c|c|c|c|c|c|c|}
\hline \multicolumn{3}{|c|}{$\begin{array}{l}\text { Staying time length in China } \\
\text { Mean }\end{array}$} & \multirow{2}{*}{$P$ value } & \multirow{2}{*}{ Push factors } & \multicolumn{5}{|c|}{ Main income source } \\
\hline $\mathrm{G}^{\mathrm{a}}(n=23)$ & $\mathrm{G}^{\mathrm{b}}(n=2)$ & $\mathrm{G}^{\mathrm{c}}(n=91)$ & & & $\mathrm{G}^{\mathrm{A}}(n=9)$ & $\mathrm{G}^{\mathrm{B}}(n=9)$ & $\mathrm{G}^{\mathrm{C}}(n=83)$ & $\mathrm{G}^{\mathrm{D}}(n=15)$ & $P$ value \\
\hline 4.435 & 4.500 & 3.945 & $0.032^{*}$ & 1 Leisure and escape & 3.344 & 3.889 & 4.108 & 4.200 & 3.344 \\
\hline 4.435 & 4.500 & 4.429 & 0.987 & 2 Togetherness and socialization & 4.444 & 4.556 & 4.434 & 4.333 & 4.444 \\
\hline 3.696 & 4.000 & 3.747 & 0.942 & 3 Knowledge and culture & 3.778 & 4.000 & 3.590 & 3.600 & 3.778 \\
\hline 4.348 & 4.500 & 4.286 & 0.855 & 4 Exploration & 3.667 & 4.111 & 4.349 & 4.600 & 3.667 \\
\hline 4.435 & 4.500 & 4.198 & 0.278 & 5 Personal interest & 4.111 & 4.000 & 3.398 & 3.067 & 4.111 \\
\hline 2.913 & 3.110 & 3.310 & $0.048^{*}$ & $\begin{array}{c}6 \text { Inner feelings and emotion } \\
\text { Pull factors }\end{array}$ & 3.556 & 3.333 & 3.048 & 2.733 & 3.556 \\
\hline 3.783 & 4.500 & 3.812 & $0.012^{*}$ & 1 Activities/events & 4.338 & 3.778 & 4.145 & 4.333 & 4.338 \\
\hline 4.043 & 4.500 & 4.022 & 0.806 & 2 Historical/cultural scenery & 4.444 & 3.889 & 3.964 & 4.267 & 4.444 \\
\hline 4.217 & 4.500 & 3.845 & $0.018^{*}$ & 3 Budget & 3.222 & 3.556 & 4.157 & 3.933 & 3.222 \\
\hline 3.913 & 4.000 & 3.637 & $0.035^{*}$ & 4 Safety and infrastructure & 4.222 & 3.333 & 3.687 & 3.600 & 4.222 \\
\hline 3.739 & 4.000 & 3.967 & $0.048^{*}$ & 5 Convenience service & 4.222 & 3.667 & 4.241 & 4.000 & 4.222 \\
\hline 3.391 & 4.500 & 3.484 & 0.368 & 6 Natural scenery & 3.444 & 3.444 & 3.759 & 4.067 & 3.444 \\
\hline 3.391 & 3.500 & 3.242 & 0.631 & 7 Source of information & 3.333 & 3.333 & 3.241 & 3.400 & 3.333 \\
\hline
\end{tabular}

(1) $G^{\text {a }}$ : governmental scholarship; $G^{b}$ : college scholarship; $G^{c}$ : family support. (2) $G^{A}$ : less than 6 months; $G^{B}$ : 6-12 months; $G^{C}: 12-24$ months; $G^{D}$ : more than 24 months. ${ }^{*}$ means $P$ value $<0.05,{ }^{* *}$ means $P$ value $<0.01$.

namely, leisure and escape from current situation, personal interest, and 3 pull factors, namely, budgets, safety and infrastructure, and propaganda sources (means $P($ sig. $)<0.05$ ). Mean value about males in leisure and escape from current situation, budgets, and propaganda sources is higher than that of female, while mean value in personal interest and safety and infrastructure is lower than that of female. Correspondingly, female travelers show more personal interest in souvenirs, local cuisine, handicrafts, and shopping and pay more attention to security. Higher level of security has more obvious stimulation on females' travel behavior. Among pull factors, source of propaganda has more positive effect on males than on females. In other words, male travelers are more likely to transfer travel advertisements online into actual travel behavior.

4.5.2. Influence of Staying Time Length in China on Travel Behavior. According to ANOVA single factor analysis, there were significant differences between respondents' travel behavior and staying time length in China, which showed obviously in 3 push factors, namely, leisure and escape from current situation, exploration of new experience, and personal interest and 4 pull factors, namely, historical and cultural resorts, activities and events, budgets, and convenient service. In factors of "leisure and escape from current situation" "exploration for new experience", mean values from group A to D increase with the growth of staying time length in China, suggesting respondents tend to enjoy leisure and explore new experience. Conversely, with the growth of staying time length in China, mean value of personal interest shows a downward trend, which indicates negative correlation between the two factors. "Historic and cultural resorts "and "activities and events" have greatest pull effects on Indonesian overseas students staying in China for less than
6 months. However, "budgets" and "convenient services" have the greatest effect on students staying in China between 1 and 2 years.

4.5.3. Influence of Main Income Source on Travel Behavior. Main income source has significant influence on respondents' travel behavior (Table 6). In general, push-pull mean values of group $B$ are significantly higher than those in other two groups. Overall indexes in group $\mathrm{C}$ are low, suggesting deficient demands for leisure and relaxing activities. On the other hand, mean values of "self cognition and emotions" are the highest, indicating the highest level of self-cognition, self-discipline, and responsibility of respondents in group C, which explained deficient demands of leisure and relaxing activities to some extent. Mean values of "events and activities," "safety and infrastructure," and "budgets" "convenient services" are highest in group A, suggesting that this group of respondents is more likely to be attracted by travel destinations with rich activities, high level safety, reasonable budgets, and convenient services.

\section{Research Discussion}

Concerning value cognition, it is suggested to explore layout strategy to combine economic benefits and culture spreading. Overseas students choose China as their destination not only for further education but also for exotic culture experience. In this study, we found that accompany relatives and friends, sharing traveling, and meet social demands are significant and core inner demands for Indonesian overseas students in China. Therefore, in the process of assaulting travel market for overseas students, we need to stress on construction of cultural value to facilitate experiencing social 
culture, so that international friendly exchange and building shared future for mankind can be achieved.

In addition, through precisely grasping overseas students characteristics, we should start from inner core factors to develop travel market for overseas students in China. According to results of this study, among factors influencing overseas students coming to China, escaping from current situation, leisure and relaxing, and feelings of freedom are greatest inner motivations, which are highly consistent with Iso-Ahola (1990) and Cromptom (1979) [17, 31]. Besides, unlike business travels or rural travels, local events, holidays, and sports events have significant pulling effects on respondents' travel behavior. In light of the findings, participatory experience and interactive cultural leisure will become the greatest attraction for overseas students in China. Meanwhile, admission ticket, accommodation, and traffic discounts are also effective pull factors to stimulate overseas students' travel passion. Thus, overseas students' special discounts could be promoted covering travel-related industries to stimulate their travel consumption.

Last but not least, we should take cooperation, coconstruction, and linkage as developing direction and promote brand cluster construction of travel destinations for overseas students. Tourism-related industries should cooperate and integrate multiple resources to form the situation of safeguard, low-cost, mutual sharing, and participation. Meanwhile, develop new modes like study tour, international events travel, theme travel, combing culture, sports, new media, and other elements, so that we can form a large-scale, systematic, and modular linkage. Establish promotion platform for overseas students, develop cross-regional travel routines, travel-related performance, and special products. Deepen cooperation and innovation in safeguard, infrastructure, product design, and payment environment to unify standard, lay down norms, and reach consensus. In the future, we need to build travel destinations meeting cultural experience needs of the overseas student group and construct brand clusters, to form group effect. We expect Indonesian students, even Southeast Asia overseas students along the Belt and Road path, can better experience Chinese culture and achieve self-improvement in such brand tourism resorts during their study in China.

Due to insufficient size and specificity of sample, universality of results in this study is limited to some extent. Despite that, this study managed to implement detailed and indepth analysis about push and pull motivators of Indonesian students' traveling behavior in China, which provides developing support and inspiration for travel market management for Southeast Asia overseas students.

\section{Data Availability}

The dataset used to support the findings of this study are available from the corresponding author upon request.

\section{Conflicts of Interest}

All the authors do not have any possible conflicts of interest.

\section{Acknowledgments}

This study was supported by the Ideological and Political Special Project of Jiangsu Education Department: Research on the Education Management of International Students based on Cross-cultural Adaptation Theory under the Background of "Double High "Construction (2020SJB0400) and the Philosophy and Social Science Research Project of Jiangsu Universities: Research on the Integrated Development Path and Mechanism of Intangible Cultural Heritage and Tourism in Southern Jiangsu (2019SJA0826).

\section{References}

[1] M. Zhang, "Research on the talent training mode Of higher vocational colleges and universities for overseas students in China from the perspective Of "One Belt, One Road"," Journal of Wuhan Polytechnic, vol. 20, no. 5, pp. 9-13, 2021.

[2] Q. Li, M. Peng, C. Zong, and Y. Jiao, "Cross-cultural broadcasting practicei the process of social media use among overseas students from "One Belt, One Road" countries in China - analysis based on cultural Reproduce Theory," New Media Research, vol. 7, no. 10, pp. 16-19, 2021.

[3] Y. Yuan and X. Shi, "Traveling market research among overseas students in Shenyang," Journal of Green Science and Technology, vol. 8, pp. 253-255, 2017.

[4] X. Zheng, "Cross-cultural traveling behavior research on overseas students in Zhejiang Province," Journal of Yangtze University, vol. 35, no. 4, pp. 185-186, 2012.

[5] C. H. Cheng, Y. S. Chen, A. K. Sangaiah, J. R. Chang, and T. Y. Wang, "Lessoning travelers' motivating behavior for a growing phenomenon in Taiwan by an advanced hybrid objectoriented hierarchical model," Journal of Computational Science, vol. 25, pp. 58-75, 2018.

[6] R. Sharpley, The Routledge Handbook of the Tourist Experience, Routledge, London, New York, 2021.

[7] A. Sangpikul, "Travel motivations Of japanese senior travellers to Thailand," International Journal of Tourism Research, vol. 10, no. 1, pp. 81-94, 2008.

[8] C. H. C. Hsu and T. Lam, "Mainland Chinese travelers' motivations and barriers Of visiting Hong Kong," Journal of Academy of Business and Economics, vol. 2, no. 1, pp. 60-67, 2003.

[9] H. Zhang and T. Lam, "An analysis Of mainland Chinese visitors' motivations to visit Hong Kong," Tourism Management, vol. 20, no. 5, pp. 587-594, 1999.

[10] G. M. S. Dann, "Anomie, ego-enhancement and tourism," Annals of Tourism Research, vol. 4, no. 4, pp. 184-194, 1977.

[11] E. L. D. Ross and S. E. Iso-Ahola, "Sightseeing tourists' motivation and satisfaction," Annals of Tourism Research, vol. 18, no. 2, pp. 226-237, 1991.

[12] Z. Hallab, "Catering to the healthy-living vacationer," Journal of Vacation Marketing, vol. 12, no. 1, pp. 71-91, 2006.

[13] F. D. Measuring and T. Motivation, "Measuring Tourist Motivation," Annals of Tourism Research, vol. 21, no. 3, pp. 555-581, 1994.

[14] T. H. Lee and J. L. Crompton, "Measuring novelty seeking in tourism," Annals of Tourism Research, vol. 19, no. 4, pp. 732-751, 1992. 
[15] S. E. Iso-Ahola, "Toward a social psychology theory of tourism motivation: a rejoinder," Annals of Tourism Research, vol. 9, no. 2, pp. 256-262, 1982.

[16] D. Wang, "Push-pull factors in mountain resorts," Chinese Geographical Science, vol. 14, no. 4, pp. 368-376, 2004.

[17] J. L. Crompton, "Motivations for pleasure vacation," Annals of Tourism Research, vol. 6, no. 4, pp. 408-424, 1979.

[18] C. Goossens, "Tourism information and pleasure motivation," Annals of Tourism Research, vol. 27, no. 2, pp. 301-321, 2000.

[19] I. Phau, S. Lee, and V. Quintal, "An investigation of push and pull motivations of visitors to private parks," Journal of Vacation Marketing, vol. 19, no. 3, pp. 269-284, 2013.

[20] D. R. Turnbull and M. Uysal, "An exploratory study of German visitors to the Caribbean:," Journal of Travel \& Tourism Marketing, vol. 4, no. 2, pp. 85-92, 1995.

[21] L. J. Chen and J. S. Chen, "The motivations and expectations of international volunteer tourists: a case study Of "Chinese village traditions"," Tourism Management, vol. 32, no. 2, pp. 435-442, 2011.

[22] P. C. Fakeye and J. L. Crompton, "Image difference between prospective, first time, and repeat vsitors to the lower Rio Grande Valley," Journal of Travel Research, vol. 29, no. 1, pp. 10-16, 1991.

[23] M. Kozak, "Comparative analysis of tourist motivations by nationality and destinations," Tourism Management, vol. 23, no. 3, pp. 221-232, 2002.

[24] Y. Wang and Y. Lo, “A study on college students' motivation for leisure travel in Macau," in Tourism and Hospitality Development between China and EU, G. Zeng, Ed., pp. 203-213, Springer, Berlin, Heidelberg, 2015.

[25] I. Azman and K. L. J. Chan, "Health and spa tourism business: tourists' profiles and motivational factors," in Health, Wellness and Tourism: Healthy Tourists, Healthy Business, L. Puczkó, Ed., pp. 9-24, Travel and Tourism Research Association Europe, Dalarna, Sweden, 2010.

[26] G. Prayag, "Senior travelers' motivations and future behavioral intentions: the case of nice," Journal of Travel \& Tourism Marketing, vol. 29, no. 7, pp. 665-681, 2012.

[27] M. Uysal and L. A. R. Hagan, "Motivation of pleasure travel and tourism," Encyclopedia of Hospitality and Tourism, vol. 21, no. 1, pp. 798-810, 1993.

[28] N. McGehee, L. Loker-Murphy, and M. Uysal, “The Australian international pleasure travel market: motivations from a gendered perspective," Journal of Tourism Studies, vol. 7, no. 1, pp. 45-57, 1996.

[29] S. S. Kim, C. K. Lee, and D. B. Klenosky, "The influence of push and pull factors at Korean national parks," Tourism Management, vol. 24, no. 2, pp. 169-180, 2003.

[30] X. Yi, T. Lan, and C. Zheng, "An empirical study on the influence of push-pull motivation and existential authenticity on loyalty: a case study of Fujian earth buildings," Human Geography, vol. 34, no. 2, pp. 143-151, 2019.

[31] S. E. Iso-ahola, "Motivation for leisure," in Understanding Leisure and Recreation, E. L. Jackson and T. L. Burton, Eds., pp. 247-279, Venture Publishing, State College, 1990. 